\title{
Stereotactic prostate adaptive radiotherapy utilising kilovoltage intrafraction monitoring: the TROG 15.01 SPARK trial
}

\author{
Paul Keall ${ }^{1 *}$, Doan Trang Nguyen ${ }^{1}$, Ricky O'Brien ${ }^{1}$, Jeremy Booth ${ }^{2}$, Peter Greer $^{3}$, Per Poulsen ${ }^{4}$, Val Gebski, \\ Andrew Kneebone ${ }^{2}$ and Jarad Martin ${ }^{3}$
}

\begin{abstract}
Background: This paper describes the multi-institutional prospective phase II clinical trial, SPARK: Stereotactic Prostate Adaptive Radiotherapy utilizing Kilovoltage Intrafraction Monitoring (KIM). KIM is a real-time image guided radiotherapy technology being developed and clinically pioneered for prostate cancer treatment in Australia. It has potential for widespread use for target radiotherapy treatment of cancers of the pelvis, thorax and abdomen.

Methods: In the SPARK trial we will measure the cancer targeting accuracy and patient outcomes for 48 prostate cancer patients who will be treated in five treatment sessions as opposed to the conventional 40 sessions. The reduced number of treatment sessions is enabled by the KIM's increased cancer targeting accuracy.

Discussion: Real-time imaging in radiotherapy has the potential to decrease the time taken during cancer treatment and reduce the imaging dose required. With the imaging being acquired during the treatment, and the analysis being automated, there is potential for improved throughput. The SPARK trial will be conducted under the auspices of the Trans-Tasman Radiation Oncology Group (TROG).
\end{abstract}

Trial registration: This trial was registered on ClinicalTrials.gov on 09 March 2015. The identifier is: NCT02397317

Keywords: Stereotactic Radiotherapy, Prostate Cancer, Kilovoltage Intrafraction Monitoring, SPARK Trial

\section{Background}

Prostate cancer stereotactic body radiation therapy (SBRT) is becoming one of radiotherapy's success stories. Technological advances such as the Cyberknife and Calypso have enabled the safe and accurate delivery of high radiation doses to the prostate cancer of eligible patients with high cure rates and low toxicity achieved in five treatment sessions as opposed to the typical 40 . Although it is going to take several years for randomized trials comparing SBRT with conventionally fractionated treatments to report, there is already a high adoption of this technology internationally: a U.S. survey showed $64 \%$ of centres were using SBRT in 2010, with the SBRT uptake growing at $\sim 10 \%$ per year, indicating that by now almost all U.S. centres will be utilising SBRT [1]. The

\footnotetext{
*Correspondence: paul.keall@sydney.edu.au

${ }^{1}$ Radiation Physics Laboratory, Sydney Medical School, The University of

Sydney, Sydney, NSW, Australia

Full list of author information is available at the end of the article
}

clinical outcome data for prostate cancer SBRT are encouraging and maturing: the recent results of a pooled analysis of 1100 patients demonstrated excellent clinical efficacy, with biochemical disease control rates of greater than $93 \%$ at five years, as well as low patient reported toxicity [2, 3]. These excellent efficacy and toxicity profiles have led to ASTRO stating that 'data supporting the use of SBRT for prostate cancer have matured to a point where SBRT could be considered an appropriate alternative for select patients' [4].

There is a history of advances in radiotherapy technology improving cancer treatment outcomes. These advances are particularly evident for prostate cancer where both image guided and intensity modulated radiotherapy (IMRT) have independently demonstrated improved tumour control and lower rates of late rectal toxicity [5-8]. However, prostate motion during cancer radiotherapy may shift the tumour outside the beam, simultaneously reducing target dose and exposing normal tissues to potentially damaging radiation 
doses. The deleterious effects of motion for prostate cancer has led ASTRO to state that 'A precise ability to localize the target tumour is essential to fully benefit from SBRT techniques' [9].

There are several solutions to account for the deleterious effects of motion during prostate cancer radiotherapy, for example the CyberKnife [10], Calypso [11, 12], RayPilot [13] and Real-Time Radiotherapy [14] systems. However, these systems use hardware that is additional to a conventional linear accelerator. A new real-time image guided radiotherapy system, Kilovoltage Intrafraction Monitoring (KIM), uses the x-ray imaging system mounted on the linear accelerator to determine the 3D position of the prostate markers, and by inference the prostate, during radiotherapy treatment. KIM has evolved through in silico studies $[15,16]$, experimental studies [17, 18], the development of a quality assurance program [19], retrospective clinical evaluations [20] and recently clinical deployment in a single institution study (NCT01742403) [21, 22] where the prostate is repositioned if the KIM-guidance system shows motion exceeding a certain threshold, typically $3 \mathrm{~mm}$ for $5 \mathrm{~s}$ for conventionally fractionated treatments and $2 \mathrm{~mm}$ for $5 \mathrm{~s}$ for SBRT treatments. The clinical success of KIM has driven the creation of the SPARK trial (NCT02397317) in which KIM will be tested in multiple institutions. This paper describes the SPARK clinical trial.

\section{Methods/Design}

The hypotheses to be tested are that in a phase II clinical trial Stereotactic Prostate Adaptive Radiotherapy utilising KIM (the SPARK trial) improves (1) Patient dose distributions, (2) Patient treatment outcomes and (3) Cancer targeting accuracy. We will test these hypotheses by performing a 48-patient clinical trial at five sites in Australia. The study schema is shown in Fig. 1.

For each treatment session for each patient, the accumulated patient dose distributions (Fig. 2) and the targeting accuracy (Fig. 3) will be determined via paired control by comparing the measured dose and targeting error with KIM to those that would have been present in the absence of KIM.

\section{Key selection criteria Inclusion}

Aged 18 years or older, histologically proven prostate adenocarcinoma, low or intermediate risk disease as defined by the NCCN guidelines: [23] a) Low Risk: All of PSA $<10$ ng/mL, Gleason Grade 6 AND Stage T1 or T2a b) Intermediate Risk: Any or all of PSA $10-20 \mathrm{ng} / \mathrm{mL}$, Gleason Grade 7 OR Stage T2b-c c) Absence of high risk features (PSA > 20, T3-4, N1 or M1 disease, Gleason score 8-10) with PSA measured within 3 months prior to enrolment, ECOG Performance status 0-2, suitable for definitive external beam radiotherapy (IMRT or VMAT), ability to have three gold fiducial markers placed in the prostate.

\section{Exclusion}

Prior lymph node irradiation, any other systemic antiprostate cancer therapy both proven in the metastatic setting and investigational (e.g. docetaxel, enzalutamide, note androgen deprivation therapy is allowed), prostate volume $>90 \mathrm{~cm}^{3}$ measured from the CT scan, patient lateral dimension $>40 \mathrm{~cm}$ as measured at the level of the prostate from the CT scan, two fiducial markers placed closer than $1 \mathrm{~cm}$ as measured in the axial CT scan, fiducial migration or fewer than 3 fiducials present in the CT scan.

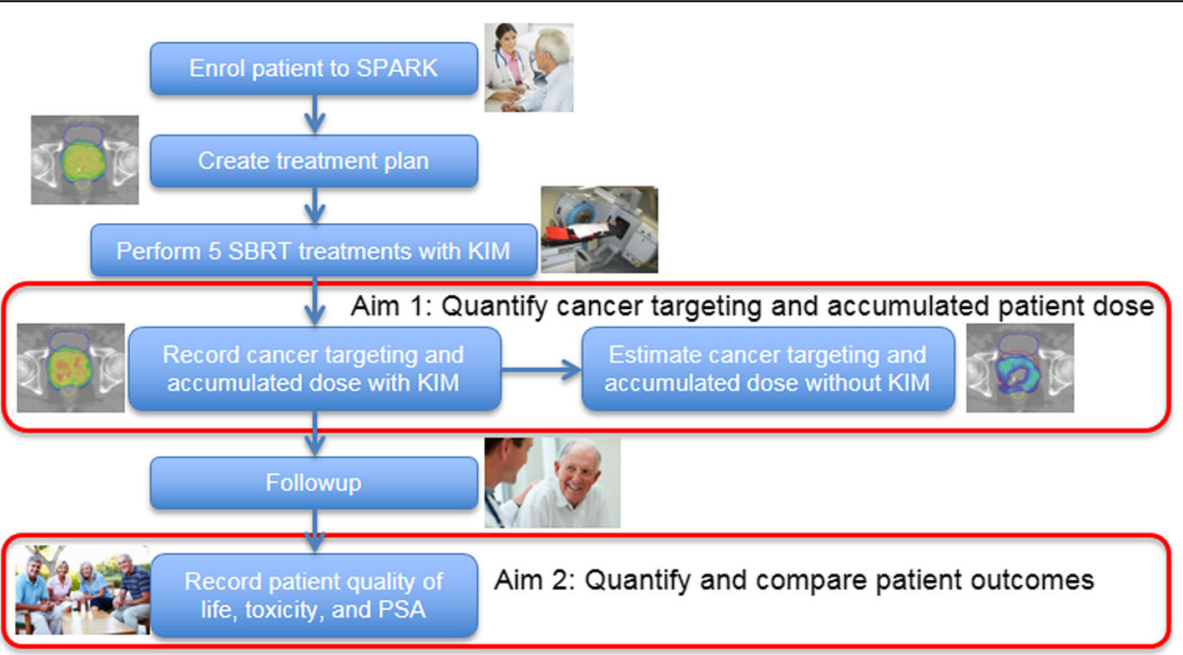

Fig. 1 The SPARK study schema 


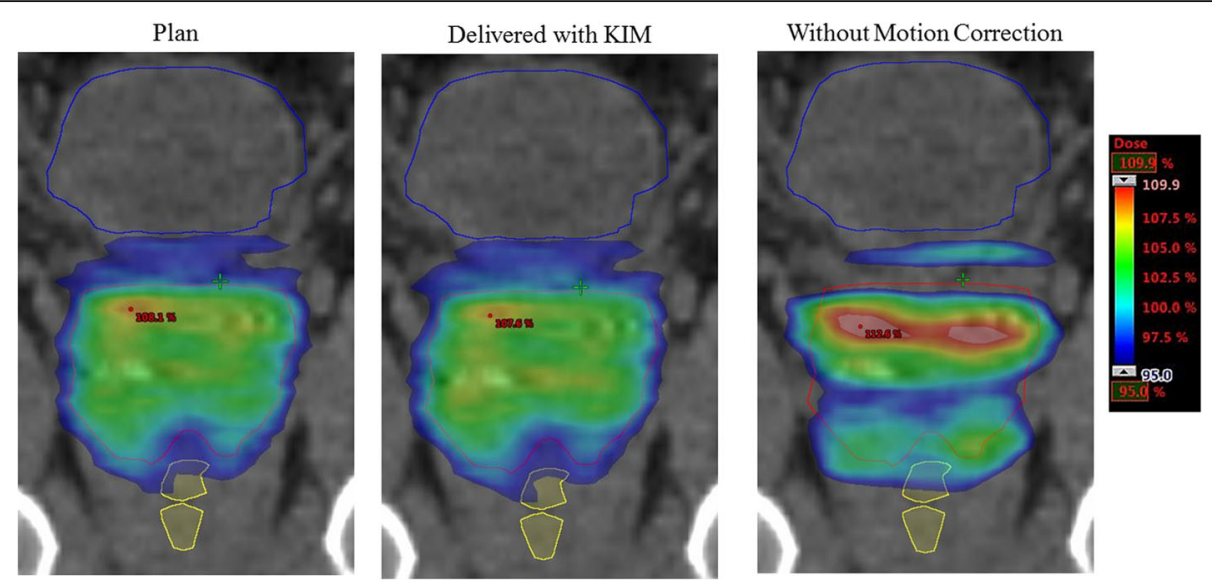

Fig. 2 The accumulated patient dose distributions will be quantified via paired control by comparing the accumulated dose distribution from the dose planned (left) with that from KIM corrections (middle) to that which would have been delivered without KIM (right)

\section{Objectives}

The primary objective is to quantify accumulated patient dose distributions with the KIM intervention compared to dose distributions estimated without the KIM intervention. Secondary objectives are to assess patient treatment outcomes, to perform a technology assessment of KIM to quantify the clinical practice impact, and to assess KIM cancer targeting accuracy.

\section{Assessments}

For each visit, prostate-specific antigen (PSA), GU and GI physician-graded toxicity (RTOG scale) and patientreported outcomes using the Expanded Prostate Cancer Index Composite (EPIC) instrument will be recorded. Where possible, and noting the limitations of retrospective comparisons, different patient cohorts and differing eligibility criteria, outcome measures will be compared with controls in participating centres and with large published series, such as the 1100-patient pooled analysis by King [2, 3] and the 477-SBRT patient series from Katz [24].

Physician-reported acute toxicity will be measured during treatment, then after treatment completion at 2 weeks, 6 weeks, 3 months, 6 months and every 6 months thereafter until 3 years after treatment. Patient reported outcomes will be at baseline, then after treatment completion at 2 weeks, 6 weeks, year 1 and year 3. Biochemical control will be assessed with PSA testing at baseline, then after treatment completion at 6 weeks, 3 months, 6 months and every 6 months thereafter until 3 years after treatment. Biochemical failure is defined using the RTOG Phoenix definition [25] (any rise in the PSA $>2 \mathrm{ng} / \mathrm{L}$ above the nadir). The estimated outcome improvements will be determined by applying established dose-response models to the patient's accumulated dose and comparing with the estimated accumulated dose distribution in the absence of the KIM intervention.

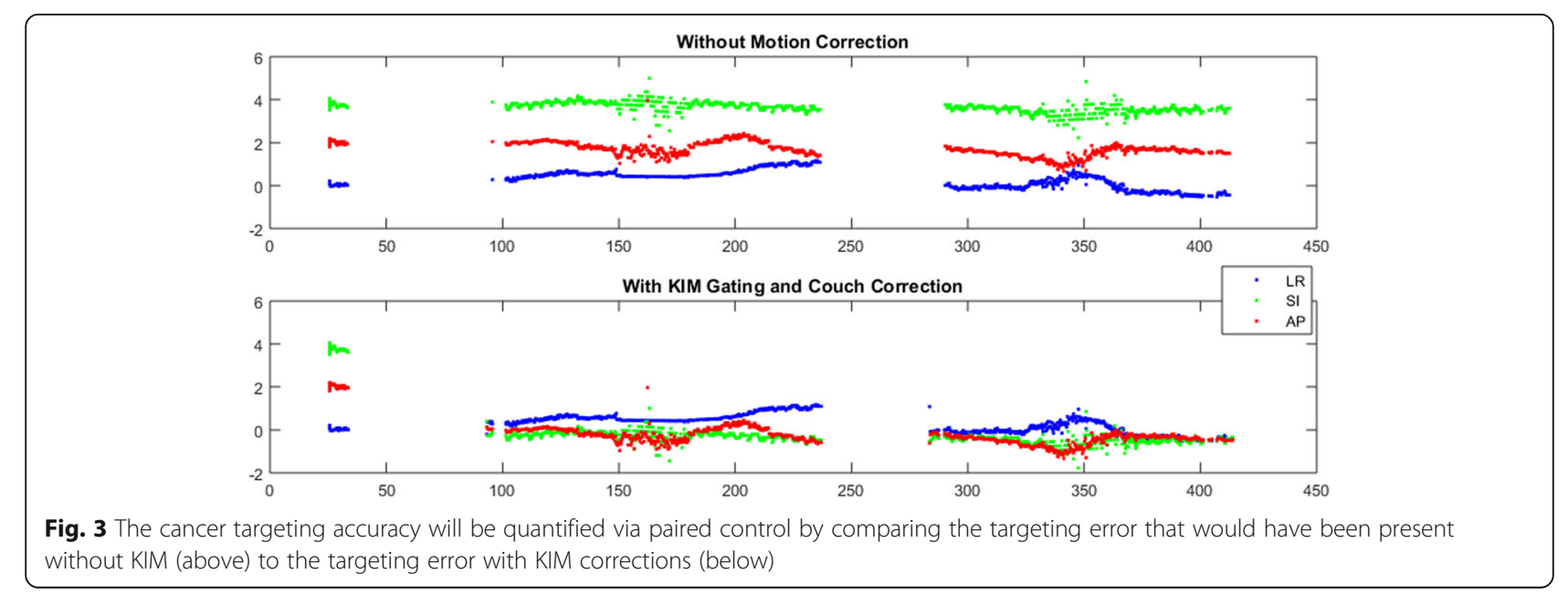




\section{Treatment planning}

Fiducial markers will be inserted prior to treatment planning. A planning $\mathrm{CT}$ is necessary for all patients. MRI is strongly encouraged but not required. Table 1 shows the guidelines for the structures needing to be contoured on the patient's CT anatomy.

The dose-volume constraints for the treatment planning are given in Table 2.

During treatment planning, the prostate volume will be assessed, patient width will be measured, and the placement, number and inter-marker distance of the fiducials will be assessed. IMRT or VMAT planning is required and both flattened and flattening filer free beams are allowed. 95\% of the PTV will be treated to the prescribed dose over the course of 5 fractions. Patients will receive 7.25 Gy per fraction in 5 treatments, consisting of 1-3 fractions per week. Treatment should not be delivered on any 2 consecutive days. Treatment should be completed over a period of no more than 5 weeks. There should be a minimum of $40 \mathrm{~h}$ and a maximum of 8 days between fractions.

\section{Treatment delivery}

Prior to the IMRT or VMAT delivery, a Cone Beam Computed Tomography (CBCT) scan will be acquired. The patient will be aligned to the planned treatment position based on the CBCT. KIM will be initiated just prior to treatment and will monitor the prostate position as the treatment beam is delivered. Two methods will be allowed to manage movement during treatment, couch

Table 1 SPARK organs at risk contouring guidelines

\begin{tabular}{ll}
\hline Structure name & Description \\
\hline Rectum & Contour as a solid structure from \\
& recto-sigmoid junction to lower \\
& aspect of ischial tuberosities, \\
& the latter of which usually \\
& corresponds to the anorectal junction. \\
& Contour the whole organ as a solid \\
Bladder & $\begin{array}{l}\text { structure. If CT and MR volumes } \\
\text { disagree, use the imaging with }\end{array}$ \\
the smaller bladder volume. & Contour from MRI, if available, \\
Penile bulb & otherwise use CT dataset. \\
Prostatic urethra planning & $\begin{array}{l}\text { Estimate urethral position, and add } \\
\text { target at risk volume (PRV) }\end{array}$ \\
add 1 mm radial expansion. If IDC in situ, \\
Please note that a dedicated urethra \\
structure (from which the Urethra_PRV \\
is created) is desirable but not mandatory. \\
Contour the Left and Right NOF as solid \\
structures to the level of the ischial \\
tuberosity. \\
Defined as the imaged volume within the \\
patient, excluding any delineated OAR \\
and the PTV. The RVR is used to identify \\
unsuspected regions of high absorbed \\
dose (ICRU 83).
\end{tabular}

shift and multileaf (MLC) tracking. If a couch shift adaptive strategy is used, when the prostate moves from its planned position by more than $2 \mathrm{~mm}$ for more than $5 \mathrm{~s}$, the treatment will be interrupted and the patient realigned based on the KIM software so that the prostate target is aligned to its planned position. Lower action thresholds and more frequent corrections are allowed at the discretion of the treatment team. If an MLC tracking adaptive strategy is used, the beam will continually be adjusted to target the prostate tumour.

\section{Sample size calculation}

We will enrol 48 patients to test the hypothesis that patient dose distributions are improved with the use of the KIM technology. The derivation follow: treating each treatment session as an independent event and then using Simon's two-stage design, a sample size of 24 sessions with intervention events will give us $90 \%$ power with $95 \%$ confidence to rule in a success rate of $2 / 3$ in favour of the futile rate of $1 / 3$. To obtain an estimated 24 treatment sessions with intervention events we need $24 / 0.10=240$ treatment sessions, which for the 5-session SBRT regime equals 48 patients. The null hypothesis will be rejected if 16 or more responses are observed in 48 patients. This design yields a type I error rate of 0.0488 and power of 0.91 when the true response rate is $67 \%$.

\section{Analysis}

An interim analysis will be performed after 20 patients have been accrued. This will correspond to an estimated 10 intervention events over 100 sessions. If four or fewer responses are observed in these 10 events, consideration will be given to the cause of the lack of response and the study may be stopped on the grounds of futility. At the same time, the IDSMC will review the trial for safety and determine whether or not it should continue. Otherwise, the study will continue with an additional 28 patients to be recruited. The main analysis will be performed after all 48 patients have completed treatment, with the final analysis being performed after the last patient has completed 2 years of follow up.

\section{Discussion}

The clinical trial SPARK: Stereotactic Prostate Adaptive Radiotherapy utilizing Kilovoltage Intrafraction Monitoring (KIM) is an example of bench-to-bedside research translation into a phase II trial. KIM is a real-time image guided radiotherapy technology being clinically pioneered in targeted prostate cancer radiotherapy. It has potential for widespread use for cancers of the pelvis, thorax and abdomen. Real-time radiotherapy has several benefits for patients. In addition to the increased geometric accuracy, leading to improve dosimetric target and normal tissue coverage - and the expected commensurate improvement 
Table 2 The treatment planning dose-volume constraints for the SPARK protocol

\begin{tabular}{|c|c|c|c|}
\hline Constraint & Per-Protocol & Minor Variation & Major Variation \\
\hline $\begin{array}{l}\text { PTV } \\
\text { D95\% }\end{array}$ & $\begin{array}{l}36.0-36.5 G y \\
(100 \%)\end{array}$ & & $<36.0 \mathrm{~Gy}$ or $>36.5$ Gy \\
\hline $\begin{array}{l}\text { PTV } \\
\text { D98\% }\end{array}$ & $\begin{array}{l}\geq 34.44 \text { Gy } \\
(95 \%)\end{array}$ & $32.72-<34.44 \mathrm{~Gy}$ & $<32.72 \mathrm{~Gy}$ \\
\hline $\begin{array}{l}\text { PTV } \\
\text { D2\% }\end{array}$ & $\begin{array}{l}\leq 38.06 \text { Gy } \\
(105 \%)\end{array}$ & $>38.06-39.96$ Gy & >39.96 Gy \\
\hline $\begin{array}{l}\text { PTV } \\
\text { Dmax to } 0.1 \mathrm{cc}\end{array}$ & $\begin{array}{l}\leq 38.78 \text { Gy } \\
(107 \%)\end{array}$ & $>38.78-40.72 \mathrm{~Gy}$ & $>40.72$ Gy \\
\hline $\begin{array}{l}\text { PTV } \\
\text { Dmax }\end{array}$ & Not within a critical structure & N/A & Within a critical structure \\
\hline $\begin{array}{l}\text { Rectum } \\
\text { Dmax to } 0.1 \mathrm{cc}\end{array}$ & $\begin{array}{l}\leq 38.06 \mathrm{~Gy} \\
(105 \%)\end{array}$ & >38.06-39.96 Gy & >39.96 Gy \\
\hline $\begin{array}{l}\text { Rectum } \\
\text { V34.4 Gy }\end{array}$ & $\leq 3 \mathrm{CC}$ & $>3-4 \mathrm{cc}$ & $>4 \mathrm{cc}$ \\
\hline $\begin{array}{l}\text { Rectum } \\
\text { V18.13 Gy }\end{array}$ & $\leq 50 \%$ & $>50-60 \%$ & $>60 \%$ \\
\hline $\begin{array}{l}\text { Rectum } \\
\text { V29 Gy }\end{array}$ & $\leq 20 \%$ & $>20-25 \%$ & $>25 \%$ \\
\hline $\begin{array}{l}\text { Rectum } \\
\text { V32.63 Gy }\end{array}$ & $\leq 5 \%$ & $>5-10 \%$ & $>10 \%$ \\
\hline $\begin{array}{l}\text { Bladder } \\
\text { Dmax to } 0.1 \mathrm{cc}\end{array}$ & $\begin{array}{l}\leq 38.06 \text { Gy } \\
(105 \%)\end{array}$ & >38.06 or 39.96 Gy & >39.96 Gy \\
\hline $\begin{array}{l}\text { Bladder } \\
\text { V34.4 Gy }\end{array}$ & $\leq 10 \subset \mathrm{cc}$ & $>10-12 c c$ & $>12 \mathrm{cc}$ \\
\hline $\begin{array}{l}\text { Bladder } \\
\text { V18.13 Gy }\end{array}$ & $\leq 50 \%$ & $>50-60 \%$ & $>60 \%$ \\
\hline $\begin{array}{l}\text { Bladder } \\
\text { V32.63 Gy }\end{array}$ & $\leq 10 \%$ & $>10-15 \%$ & $>15 \%$ \\
\hline $\begin{array}{l}\text { Urethra_PRV } \\
\text { Dmax } 0.1 \mathrm{cc}\end{array}$ & $\begin{array}{l}\leq 38.78 \text { Gy } \\
(107 \%)\end{array}$ & $>38.78-40.72$ Gy & >40.72 Gy \\
\hline $\begin{array}{l}\text { Urethra_PRV } \\
\text { V38.0 Gy }\end{array}$ & $\leq 5 \%$ & $>5-7 \%$ & $>7 \%$ \\
\hline $\begin{array}{l}\text { FemHead_R, FemHead_L } \\
\text { V20 Gy }\end{array}$ & $\leq 10 \subset \mathrm{cC}$ & $>10-14 \mathrm{cc}$ & $>14 \mathrm{cc}$ \\
\hline $\begin{array}{l}\text { FemHead_R, FemHead_L } \\
\text { Dmax to } 0.1 \text { cc }\end{array}$ & $\leq 30 \mathrm{~Gy}$ & $>30-32$ Gy & $>32 \mathrm{~Gy}$ \\
\hline $\begin{array}{l}\text { PenileBulb } \\
\text { Dmax } 0.1 \mathrm{cc}\end{array}$ & $\leq 36.25$ Gy & $\mathrm{n} / \mathrm{a}$ & $\mathrm{n} / \mathrm{a}$ \\
\hline $\begin{array}{l}\text { PenileBulb } \\
\text { V20 Gy }\end{array}$ & $\leq 1 \mathrm{cC}$ & $\mathrm{n} / \mathrm{a}$ & $\mathrm{n} / \mathrm{a}$ \\
\hline $\begin{array}{l}\text { Intermediate dose spillage: ratio of } \\
\text { volumes receiving 50\% TD to 100\% TD }\end{array}$ & $\leq 4$ & $>4-5$ & $>5$ \\
\hline $\begin{array}{l}\text { Conformity Index (volume receiving } \\
36.25 \\
\text { Gy/volume of PTV): }\end{array}$ & $\leq 1.1$ & $>1.1-1.2$ & $>1.2$ \\
\hline $\begin{array}{l}\text { RVR } \\
\text { V36.25 Gy }\end{array}$ & $\leq 5 \mathrm{CC}$ & $>5-7 \mathrm{cc}$ & $>7 \mathrm{cc}$ \\
\hline
\end{tabular}

in clinical outcomes - real-time radiotherapy has the potential to improve the throughput of cancer treatments and reduce the imaging dose required.

The improvement in throughput comes as the realtime imaging can replace the time consuming pre- treatment and intra-treatment volumetric imaging procedures, such as cone beam $\mathrm{CT}$, as well as the time taken to analyse these images. With the imaging being acquired during the treatment, and the analysis being automated, there is potential for improved throughput. 
The reduction in the imaging dose is due to the elimination in the use of repeat cone beam CT scans before treatment, and the elimination of the use of cone beam CT scans between treatments. Though KIM does use the $\mathrm{x}$-ray imager during treatment, the reduced field size $6 \times 6 \mathrm{~cm}^{2}$ compared to $\geq 25 \times 25 \mathrm{~cm}^{2}$ with cone beam CT for each projection - means a much lower imaging dose, even if the number of projections is higher and/or the dose per image is higher.

\section{Abbreviations}

ASTRO: American Society for Radiation Oncology; IDSMC: Independent Data Safety Monitoring Committee; IMRT: Intensity Modulated Radio Therapy; KIM: Kilovoltage Intrafraction Monitoring; MLC: Multileaf Collimator; PSA: Prostate-Specific Antigen; SBRT: Stereotactic Body Radiation Therapy; SPARK: Stereotactic Prostate Adaptive Radiotherapy utilising Kilovoltage Intrafraction Monitoring; TROG: Trans-Tasman Radiation Oncology Group (TROG Cancer Research); VMAT: Volumetric Modulated Arc Therapy

\section{Acknowledgements}

The authors acknowledge the substantial time from many people who have worked diligently on the SPARK trial including TROG Cancer Research, radiation oncologists, medical physicists, radiation therapists, clinical trial co-ordinators and lawyers. This input is essential to allow the SPARK trial to enrol patients and maximise the chance of successful outcomes. We acknowledge and thank Shona Silvester and Julie Baz for the manuscript compilation, formatting and editing.

\section{Funding}

The SPARK trial is co-funded by the Prostate Cancer Foundation of Australia and Cancer Australia.

\section{Availability of data and materials}

Not applicable.

\section{Authors' contributions}

PK and DTN drafted the manuscript and will analyse the clinical trial data. PK is an inventor of the KIM technology and participated in the design of this clinical trial. RO, PP and DTN developed the software for use in the intervention. JB, PG, AK and JM contributed to the clinical trial study design. VG developed the statistical methodology for the clinical trial. All authors read and approved the final manuscript.

\section{Competing interests}

Authors Keall and Poulsen are inventors on an issued patent related to the KIM technology that is licensed from Stanford University to Varian Medical Systems. Authors Keall, O'Brien and Poulsen are inventors on an issued patent related to the KIM technology that is unlicensed.

\section{Consent for publication}

Not applicable.

\section{Ethics approval and consent to participate}

The protocol for this clinical trial has been reviewed and approved on 19 June 2015 by the Hunter New England Human Research Ethics Committee (HREC). This Human Research Ethics Committee is constituted and operates in accordance with the National Health and Medical Research Council's 'National Statement on Ethical Conduct in Human Research (2007)' (National Statement). All patients must provide written informed consent before being enrolled in the trial.

\section{Author details}

${ }^{1}$ Radiation Physics Laboratory, Sydney Medical School, The University of Sydney, Sydney, NSW, Australia. ${ }^{2}$ Department of Radiation Oncology, Northern Sydney Cancer Centre, Sydney, NSW, Australia. ${ }^{3}$ Department of Radiation Oncology, Calvary Mater Newcastle, Newcastle, NSW, Australia. ${ }^{4}$ Department of Oncology, Aarhus University Hospital, Aarhus, Denmark. ${ }^{5}$ University of Sydney NHMRC Clinical Trials Centre, Sydney, NSW, Australia.
Received: 14 November 2016 Accepted: 2 March 2017

Published online: 08 March 2017

\section{References}

1. Pan H, Simpson DR, Mell LK, Mundt AJ, Lawson JD. A survey of stereotactic body radiotherapy use in the United States. Cancer. 2011;117:4566-72.

2. King CR, Collins S, Fuller D, Wang P-C, Kupelian P, Steinberg M, Katz A. Health-Related Quality of Life After Stereotactic Body Radiation Therapy for Localized Prostate Cancer: Results From a Multi-institutional Consortium of Prospective Trials. Int J Radiat Oncol Biol Phys. 2013;87:939-45.

3. King CR, Freeman D, Kaplan I, Fuller D, Bolzicco G, Collins S, Meier R, Wang J, Kupelian P, Steinberg M, Katz A. Stereotactic body radiotherapy for localized prostate cancer: Pooled analysis from a multi-institutional consortium of prospective phase II trials. Radiother Oncol. 2013;109:217-21.

4. ASTRO Model Policy, Stereotactic Body Radiation Therapy. ASTRO web site 2013.

5. Zelefsky MJ, Kollmeier M, Cox B, Fidaleo A, Sperling D, Pei X, Carver B, Coleman J, Lovelock M, Hunt M. Improved clinical outcomes with highdose image guided radiotherapy compared with non-IGRT for the treatment of clinically localized prostate cancer. Int J Radiat Oncol Biol Phys. 2012;84:125-9.

6. Singh J, Greer PB, White MA, Parker J, Patterson J, Tang Cl, Capp A, Wratten C, Denham JW. Treatment-Related Morbidity in Prostate Cancer: A Comparison of 3-Dimensional Conformal Radiation Therapy With and Without Image Guidance Using Implanted Fiducial Markers. Int J Radiat Oncol Biol Phys. 2013;85:1018-23.

7. Gill S, Thomas J, Fox C, Kron T, Rolfo A, Leahy M, Chander S, Williams S, Tai KH, Duchesne $G$, Foroudi F. Acute toxicity in prostate cancer patients treated with and without image-guided radiotherapy. Radiat Oncol. 2011;6:145.

8. Ratnayake G, Martin J, Plank A, Wong W. Incremental changes verses a technological quantum leap: The additional value of intensity-modulated radiotherapy beyond image-guided radiotherapy for prostate irradiation. J Med Imaging Radiat Oncol. 2014;n/a-n/a

9. Report of the ASTRO Emerging Technology Committee. Stereotactic Body Radiotherapy (SBRT) For Primary Management of Early-Stage, LowIntermediate Risk Prostate Cancer. 2008.

10. King CR, Brooks JD, Gill H, Pawlicki T, Cotrutz C, Presti JC. Stereotactic body radiotherapy for localized prostate cancer: interim results of a prospective phase II clinical trial. Int J Radiat Oncol Biol Phys. 2009;73:1043-8.

11. Kupelian P, Willoughby T, Mahadevan A, Djemil T, Weinstein G, Jani S, Enke C, Solberg T, Flores N, Liu D, Beyer D, Levine L. Multi-institutional clinical experience with the Calypso System in localization and continuous, realtime monitoring of the prostate gland during external radiotherapy. Int J Rad Onc Biol Phys. 2007;67:1088-98.

12. Sandler HM, Liu P-Y, Dunn RL, Khan DC, Tropper SE, Sanda MG, Mantz CA Reduction in Patient-reported Acute Morbidity in Prostate Cancer Patients Treated With 81-Gy Intensity-modulated Radiotherapy Using Reduced Planning Target Volume Margins and Electromagnetic Tracking: Assessing the Impact of Margin Reduction Study. Urology. 2010;75:1004-8.

13. Lindencrona U, Braide K, Syrén H, Hertzman S, Kindblom J. Clinical Experience of Real-Time Tracking with the Raypilot System in Patients with Prostate Cancer (ESTRO Poster). Radiother Oncol. 2012;103:S531.

14. Kitamura K, Shirato H, Seppenwoolde Y, Onimaru R, Oda M, Fujita K, Shimizu S, Shinohara N, Harabayashi T, Miyasaka K. Three-dimensional intrafractional movement of prostate measured during real-time tumor-tracking radiotherapy in supine and prone treatment positions. Int J Radiat Oncol Biol Phys. 2002;53:1117-23.

15. Poulsen PR, Cho B, Keall PJ. Real-time prostate trajectory estimation with a single imager in arc radiotherapy: a simulation study. Phys Med Biol. 2009; 54:4019-35.

16. Poulsen PR, Cho B, Langen K, Kupelian P, Keall PJ. Three-dimensional prostate position estimation with a single $x$-ray imager utilizing the spatial probability density. Phys Med Biol. 2008;53:4331-53.

17. Poulsen PR, Cho B, Sawant A, Keall PJ. Implementation of a new method for dynamic multileaf collimator tracking of prostate motion in arc radiotherapy using a single kV imager. Int J Radiat Oncol Biol Phys. 2010;76:914-23.

18. Poulsen PR, Cho B, Sawant A, Ruan D, Keall PJ. Dynamic MLC tracking of moving targets with a single $\mathrm{KV}$ imager for 3D conformal and IMRT treatments. Acta Oncol. 2010:49:1092-100.

19. Ng J, Booth J, O'Brien R, Colvill E, Huang C-Y, Poulsen PR, Keall P. Quality assurance for the clinical implementation of kilovoltage intrafraction monitoring for prostate cancer VMAT. Med Phys. 2014;41:111712. 
20. Ng JA, Booth JT, Poulsen PR, Fledelius W, Worm ES, Eade T, Hegi F, Kneebone A, Kuncic Z, Keall PJ. Kilovoltage intrafraction monitoring for prostate intensity modulated arc therapy: first clinical results. Int J Radiat Oncol Biol Phys. 2012;84:e655-61.

21. Keall PJ, Ng JA, Juneja P, O'Brien RT, Huang C-Y, Colvill E, Caillet V, Simpson E, Poulsen PR, Kneebone A. Real-Time 3D Image Guidance Using a Standard LINAC: Measured Motion, Accuracy, and Precision of the First Prospective Clinical Trial of Kilovoltage Intrafraction Monitoring-Guided Gating for Prostate Cancer Radiation Therapy. Int J Radiat Oncol Biol Phys. 2016;94: 1015-21.

22. Keall PJ, Ng JA, O'Brien R, Colvill E, Huang C-Y, Poulsen PR, Fledelius W, Juneja P, Simpson E, Bell L. The first clinical treatment with kilovoltage intrafraction monitoring (KIM): A real-time image guidance method. Med Phys. 2015;42:354-8.

23. National Comprehensive Cancer Network. NCCN Clinical Practice Guidelines in Oncology: Prostate Cancer. 2016.

24. Katz AJ, Kang J. Stereotactic body radiotherapy as treatment for organ confined low-and intermediate-risk prostate carcinoma, a 7-year study. Front Oncol. 2014;4:240.

25. Roach III M, Hanks G, Thames Jr H, Schellhammer P, Shipley WU, Sokol GH, Sandler $\mathrm{H}$. Defining biochemical failure following radiotherapy with or without hormonal therapy in men with clinically localized prostate cancer: Recommendations of the RTOG-ASTRO Phoenix Consensus Conference. Int J Radiat Oncol Biol Phys. 2006;65:965-74.

\section{Submit your next manuscript to BioMed Central} and we will help you at every step:

- We accept pre-submission inquiries

- Our selector tool helps you to find the most relevant journal

- We provide round the clock customer support

- Convenient online submission

- Thorough peer review

- Inclusion in PubMed and all major indexing services

- Maximum visibility for your research

Submit your manuscript at www.biomedcentral.com/submit 